\section{Tropical Journal of Ophthalmology and Otolaryngology}

\title{
A rare case report of Coats' disease
}

\section{Madan Kulkarni V. ${ }^{1 *}$, Madhukar Sabnis M. ${ }^{2}$, Kailashbhai Kalaria H. ${ }^{3}$, Vivek Agarwal H. ${ }^{4}$ DOI: https://doi.org/10.17511/jooo.2020.i07.05}

1* Vedesh Madan Kulkarni, Resident, Department of Ophthalmology, Dr. D Y Patil Medical College, Hospital \& Research Institute, Kolhapur, Maharashtra, India.

2 Milind Madhukar Sabnis, Professor and Head of Department, Department of Ophthalmology, Dr. D Y Patil Medical College, Hospital \& Research Institute, Kolhapur, Maharashtra, India.

3 Hardik Kailashbhai Kalaria, Resident, Department of Ophthalmology, Dr. D Y Patil Medical College, Hospital \& Research Institute, Kolhapur, Maharashtra, India.

4 Himali Vivek Agarwal, Resident, Department of Ophthalmology, Dr. D Y Patil Medical College, Hospital \& Research Institute, Kolhapur, Maharashtra, India.

Coats' disease was first described by George Coats, as a unilateral retinal vascular abnormality. Coats' disease is a nonhereditary, idiopathic disease presenting with vascular telangiectasia with intraretinal and subretinal exudation with no racial preponderance and systemic associations. Coats' disease presents with a wide ambit of clinical features- vision loss, strabismus, leukocoria, or nystagmus. The three classical features that are pathognomonic of Coats' are exudative retinal detachment, telangiectatic vessels, and peripheral retinal ischemia. The modalities for treatment of Coats disease that can be used are laser photocoagulation, anti-VEGF agents, or a combination of both and cryotherapy. This article describes a case report of a 10-year-old male child with complaints of painless loss of vision, his ophthalmological evaluation, and the treatment is undertaken.

Keywords: Coats disease, Exudation, Telangiectasia

\section{Corresponding Author}

Vedesh Madan Kulkarni, Resident, Department of Ophthalmology, Dr. D Y Patil Medical College, Hospital \& Research Institute, Kolhapur, Maharashtra, India. Email: vedesh1983@gmail.com
How to Cite this Article

To Browse

Kulkarni VM, Sabnis MM, Kalaria HK, Agarwal HV. A rare case report of Coats' disease. Trop J Ophthalmol Otolaryngol. 2020;5(7):194-199.

Available From

https://opthalmology.medresearch.in/index.php/jooo /article/view/166

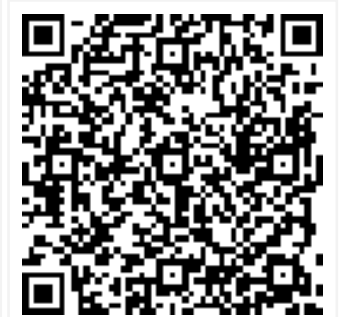

Manuscript Received 2020-09-29

Conflict of Interest No
Review Round 1 2020-10-09

Funding
Review Round 2 2020-10-16

Ethical Approval Yes
Review Round 3

Accepted 2020-10-19

(C) 2020 by Vedesh Madan Kulkarni, Milind Madhukar Sabnis, Hardik Kailashbhai Kalaria, Himali Vivek Agarwal and Published by Siddharth Health Research and Social Welfare Society. This is an Open Access article licensed under a Creative Commons Attribution 4.0 International License https://creativecommons.org/licenses/by/4.0/ unported [CC BY 4.0]
Note 


\section{Introduction}

Coats' disease was first described by George Coats in 1908, as unilateral retinal vascular abnormality [1]. It was followed by Leber reporting a different syndrome showing multiple retinal aneurysms, associated with retinal degeneration [2]. In 1955, Reese elaborated on the features described by Coats and Leber and concluded that they were varying presentations of the same disease complex with retinal telangiectasia being the underlying pathology, eventually leading to progressive exudation and retinal detachment [3]. The most noteworthy and assertive account of Coats' Disease came from Shields et al., in 2000 Sanford Gifford Memorial Lecture, who used strict guidelines to diagnose Coats disease and differentiate from other simulating conditions [4]. Earlier Coats' Disease was used as an umbrella term to describe an array of exudative retinal vasculopathy. However, the Shields study defined Coats disease as idiopathic retinal telangiectasia with intraretinal and/or subretinal exudation without appreciable retinal or vitreal traction [4]. Retinal telangiectasia was defined as dilated, irregular caliber, small- to medium-sized retinal blood vessels. The term exudative retinopathy was used for yellow exudation in the sensory retina or subretinal space [5].

Coats' disease typically occurs in young males and is diagnosed in the first or second decades of life. Patients can present with a range of symptoms and signs, with the most common being decreased visual acuity, strabismus, and leukocoria. The three classical features that are pathognomonic of Coats' are exudative retinal detachment, telangiectatic vessels, and peripheral retinal ischemia. There are various modalities to confirm the clinical suspicion of Coats' disease. Although it is possible to reach to diagnosis from clinical examination alone, in the majority of cases, some form of ancillary testing such as fluorescein angiography, Optical Coherence Tomography(OCT), B-Scan, computerized tomography (CT), and magnetic resonance imaging (MRI) is needed.

\section{Case report}

A 10-year-old male patient came to the Ophthalmology OPD at Dr. D. Y. Patil Medical College, Hospital \& Research Institute, Kolhapur with unilateral gradual painless diminution of vision in the left eye which progressed over years to current visual acuity.
Diurnal variation in visual acuity was not seen. There was no history of systemic diseases. Family history showed that there were no such symptoms in any of the family members.

The birth history of the patient revealed a nonconsanguineous marriage. There were no complications during the antenatal or intra-natal period to mother or child. The patient was full-term born of normal vaginal delivery, with normal birth weight, with no NICU admission or cyanosis or feeding difficulties. There was no delay in developmental milestones noted by the parents.

\section{Examination}

General examination: The patient is conscious, cooperative, well-oriented to time, place, and person. The patient was afebrile with a normal pulse and blood pressure.

Ophthalmological examination:

Slit-lamp examination revealed anterior segment was normal in the right eye and Leucocoria (amaurotic cat-eye reflex) in the left eye. Unaided visual acuity of the right eye is $6 / 6$ and the left eye is $6 / 36$ with pinhole not improving.

According to the classification of Coats disease given by Shields, the patient was with class $2 \mathrm{~B}$ with foveal exudation. 4

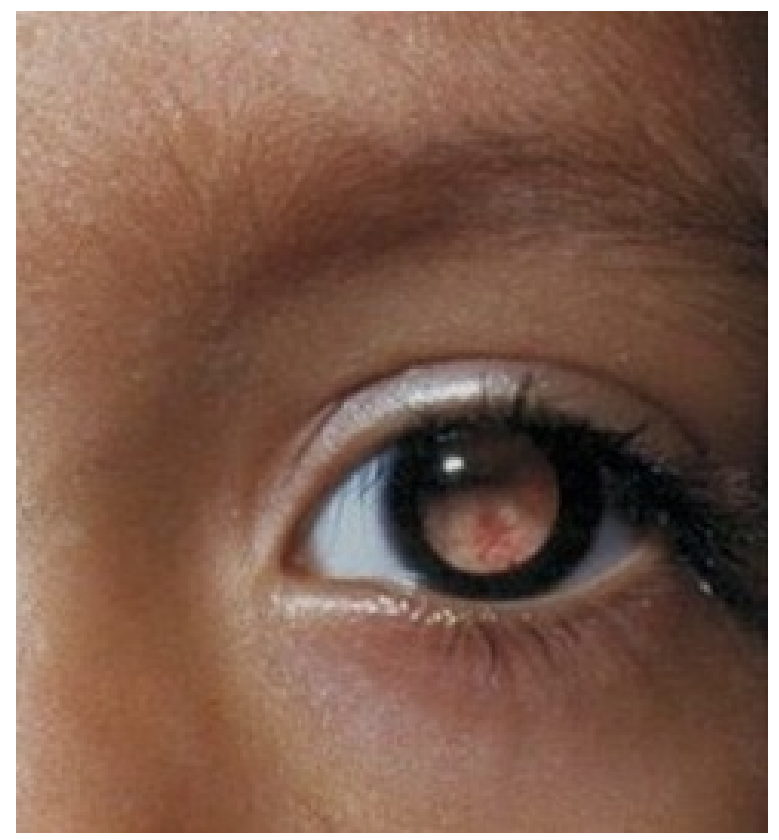

Fig-1: Leucocoria. 


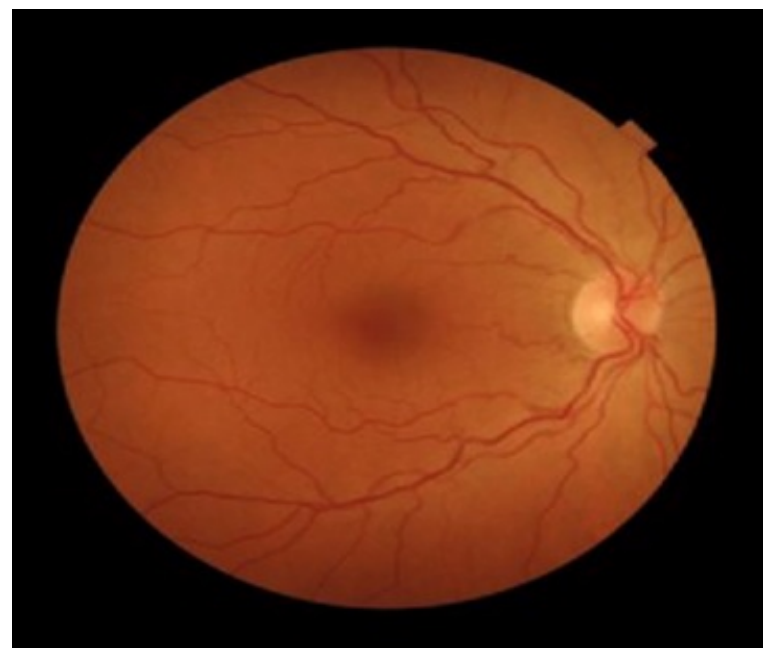

Fig-2: Right eye Fundus is within normal limits.

(Image was taken with Optomed Smartscope M5 fundus camera)

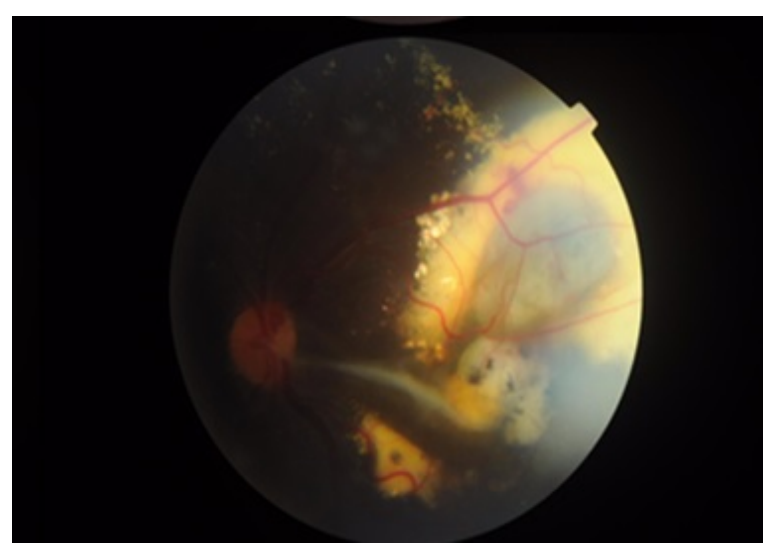

Fig-3: Left eye fundus showing aneurysmal dilatation.

Telangiectasia, intraretinal and subretinal exudates involving the macula and lipid deposits.

(Images were taken with Optomed Smartscope M5 fundus camera)

Systemic examination: Cardio-vascular, central nervous system, respiratory system, and per abdominal system were all within normal limits.

Because of the substantial and intensifying nature of the disease, laser photocoagulation was scheduled,532 $\mathrm{nm}$ laser photocoagulation, using a laser indirect ophthalmoscope delivery system, was performed to the telangiectatic vessels and peripheral capillary non-perfusion areas in the left eye.

\section{Discussion}

Several studies conducted in the Western population as well as in the Indian scenario have irrefutable evidence proving the male preponderance of Coats' disease, with the presenting age showing a bimodal pattern peaking in the second and fifth decade of life [6]. As compared to Western literature and most available Indian accounts that unequivocally advocate the unilateral nature of Coats disease $[4,5,7]$, however, a study suggested the bilateral presentation of the disease entity in the Indian subset [6].

Coats' disease is non-hereditary, sporadic with no racial preponderance and systemic associations. Coats' disease presents with a wide ambit of clinical features- vision loss, strabismus, leukocoria, or nystagmus. Despite chiefly being a retinal pathology, it presents with significant anterior segment abnormalities including corneal edema, megalocornea, shallow anterior chamber, anterior chamber cholesterolosis, neovascularization of iris, and resultant iris heterochromia, and cataract [5].

The extent of presentation is highly variable; Although the condition is progressive, it can be asymptomatic only to be later diagnosed on ophthalmoscopy [8]. It has been observed that the younger the age of presentation, the more severe is the condition and is associated with poorer visual prognosis. Patients who present at a later age may have possibly been asymptomatic in their childhood.

Table-1: Staging of the disease is done based on the extent and the quadrant(s) of the retina involved [9].

\begin{tabular}{|l|l|}
\hline Zone & Extent \\
\hline I & Macula- area between temporal vascular arcades \\
\hline II & Mid periphery- between the retinal vascular arcades and equator \\
\hline III & Peripheral fundus anterior to the above \\
\hline
\end{tabular}

Table-2: Classification of Coats disease [4].

\begin{tabular}{|l|l|}
\hline \multicolumn{1}{|c|}{ Retinal telangiectasia only } \\
\hline 2 & Telangiectasia and exudation \\
\hline 2A & Extrafoveal exudation \\
\hline $2 B$ & Foveal exudation \\
\hline 3 & Exudative retinal detachment \\
\hline $3 \mathrm{~A}$ & Subtotal detachment \\
\hline 3A1 & Extrafoveal \\
\hline $3 \mathrm{~A} 2$ & Foveal \\
\hline $3 \mathrm{~B}$ & Total retinal detachment \\
\hline 4 & Total retinal detachment and glaucoma \\
\hline 5 & Advanced end-stage disease \\
\hline
\end{tabular}


A staging classification of Coats disease was put forward by Shields et al. based on their observations. An updated classification has been suggested with stage $2 \mathrm{~B}$ being subdivided into stage 2B1 without subfoveal nodule and stage 2B2 with subfoveal nodule since the presence of a subfoveal nodule significantly affects the visual outcome.10

Two pathological processes are known to occur in Coats' disease $[11,12]$.

- Endothelial level changes of the retinal vasculature cause breakdown of the bloodretinal barrier. Following this, plasma leaks into the vessel wall causing thickening and "sausage-like" shape of vessels.

- Damaged endothelium along with abnormal pericytes leads to bulging of the vessels and the characteristic telangiectasia.

This pathogenic vasculature causes retinal hypoxia and exudation of lipids from these vessels is responsible for retinal detachment, retinal thickening, and retinal cyst formation.

Most commonly seen complications of Coats' are caused by chronic retinal detachment. Patients may present with a painful blind eye due to neovascular glaucoma as a result of iris and angle neovascularisation. Although there are marked retinal ischemia, retinal neovascularisation is infrequent and so is the occurrence of vitreous and retinal hemorrhage. Retinal macrocysts occur as degenerative changes and are seen often as the duration of retinal detachment increases.

Anterior chamber cholesterolosis is an unusual complication that develops most likely as a result of the migration of cholesterol crystals from the exudates in the subretinal space into the anterior chamber possibly through retinal dialysis [13].

The most important differential diagnosis of Coats' is retinoblastoma and may often lead to unnecessary enucleation in patients. Other differentials include- Persistent hyperplastic primary vitreous (PHPV), toxocariasis.

Other diseases showing exudative detachment are retinopathy of prematurity, familial exudative retinopathy, and Norrie disease. Some disease entities showing leukocoria include retinal hemorrhage, hemangioblastoma, choroidal hemangioma, coloboma, endophthalmitis, cytomegalovirus retinitis, and toxoplasmosis.
Although several modalities are present to diagnose Coats' and more so differentiate it from the abovementioned entities, fundus examination remains the most unambiguous diagnostic approach towards Coats'. Retinal telangiectasia is a universal finding, described as "light bulb telangiectasias" because of the bulbous terminal configuration and associated extensive yellow exudation [14].

The inferior and temporal quadrants are most commonly involved. Intraretinal exudation is present in almost all cases and can be widespread and away from the telangiectasia. Ultrasound and CT scans are also helpful in ruling out other differentials especially retinoblastoma. MRI aids in the diagnosis of advanced Coats' disease.

Fluorescein angiography shows hyperfluorescence of the retinal telangiectasia in the venous phase, areas of capillary dropouts, early hypofluorescence in the areas of retinal exudation with late staining and late leakage from the abnormal vessels, macular edema, and neovascularization of disc retina and iris [7]. Optical coherence tomography (OCT) assists in the representation of cystoid macular edema, epiretinal membrane, vitreomacular traction, subretinal/intraretinal fluid, central macular thickness, and subfoveal choroidal thickness [7].

In our case, both male gender and unilateral presentation are in line with the usual presentation of Coats' disease, as seen in a case presented in the Medical Journal Armed Forces India (2013), which also states that the male proclivity of the disease in South India is $83.4 \%$ and unilateral involvement is $90 \%$ [15]. The absence of family history is suggestive of the sporadic nature of Coats'.

The patient complained of gradual painless diminution of vision which is the most common presenting complaint as per the studies reviewed $[15,16]$. Anterior segment was normal which is a distinctive finding as the Indian population is seen to have a higher preponderance of anterior segment pathologies (cataract, neovascularization of the iris, anterior chamber cells, flare and cholesterolosis, corneal edema, and raised IOP), as per the same study [15].

A case published in the Delhi Journal of Ophthalmology, 2017 [16] reported adult-onset of Coats' at the age of 55 years with visual acuity of $6 / 6$ with similar findings as our case, on fundus evaluation: diffuse telangiectasias with lipid exudates and associated exudative intraretinal and subretinal detachment. 
However, contrary to young patients, adult presentation of Coats' shows stable visual acuity and slower progression, and more local involvement. Young patients with macular involvement with diffuse retinal detachment show poor visual prognosis. Since there is a lacunae in the universal guidelines for the treatment of Coats' disease, we aimed our therapy towards the telangiectatic vessels and non-perfusion areas. We preferred photocoagulation as the treatment of choice, as the presentation was still timely with the presence of localized exudation and detachment. Other higher modalities for treatment that can be used are Anti VEGF agents with or without argon laser photocoagulation and cryotherapy. The patient was eventually lost to follow up, however, other studies suggest a fair prognosis with such a line of treatment and substantial improvement in visual acuity.

\section{Conclusion}

Coats' is a nonhereditary, sporadic disease presenting with vascular telangiectasia with intraretinal and subretinal exudation with no racial preponderance and systemic associations. The three classical features that are pathognomonic of Coats' are exudative retinal detachment, telangiectatic vessels, and peripheral retinal ischemia.

The modalities for treatment of Coats disease that can be used are laser photocoagulation, anti-VEGF agents, or a combination of both, cryotherapy, and surgery for retinal detachment. Greater knowledge about the typical features, diagnosing the disease at an early stage, and initiating appropriate treatment can greatly improve the visual outcomes and reduce the rate of enucleation in Coats disease.

\section{Reference}

01. Coats G. Forms of retinal diseases with massive exudation. Roy Lond Ophthalmol Hosp Rep. $1908 ; 17 ; 440-525$.

[Crossref]

02. Leber T. Ueber eine durch Vorkommen multiple Miliaraneury men charakterisiert Form von Retinal degeneration. Albrecht von Graefe, Arch Klin Ophthalmol. 1912;81:1-14. [Crossref]

03. Reese AB. Telangiectasis of the retina and Coats disease. Am J Ophthalmol. 1956;42(2)1-8. doi: 10.1016/0002-9394(56)90002-2 [Crossref]
04. Shields JA, Shields CL, Honavar SG, DeMirci H. Clinical variations and complications of Coats' disease in 150 cases- The 2000 Sanford Gifford memorial lecture. Am J Ophthalmol. $2001 ; 131$ (5)561-571.

doi: 10.1016/s0002-9394(00)00883-7 [Crossref]

05. Mrittika S, Carol LS, Santosh GH, Shields JA. Coats disease- An overview of classification, management and outcomes. Indian J Ophthalmol. 2019;67(6)763-771. doi: 10.4103/ijo.IJO_841_19 [Crossref]

06. Rishi P, Rishi E, Uparkar M, Sharma T, Gopal L, Bhende $P$, et al. Coats' disease- An Indian perspective. Indian J Ophthalmol. 2010;58(2)119-124. doi: $10.4103 / 0301-4738.60081$ [Crossref]

07. Shields CL, Udyaver S, Dalvin LA, Lim LAS, Atalay HT, Khoo CTL, et al. Coats disease in 351 eyes- Analysis of features and outcomes over 45 years (by decade) at a single center. Indian J Ophthalmol. 2019;67(6)772-783.

doi: 10.4103/ijo.IJO_449_19 [Crossref]

08. Haller JA. Coats' disease and Retinal Telangeclasia in Ophthalmology. 2nd ed, InMyron Y, Duker JS, US- Mosby. 2006.

[Crossref]

09. Budning AS, Heon E, Gallie BL. Visual prognosis of Coats' disease. Journal of American Association for Pediatric Ophthalmology and Strabismus. $1998 ; 2(6) 356-359$.

doi: 10.1016/s1091-8531(98)90034-9 [Crossref]

10. Daruich AL, Moulin AP, Tran HV, Matet A, Munier FL. Subfoveal nodule in Coats disease- Toward an updated classification predicting visual prognosis. Retina (Philadelphia, Pa). 2017;37(8)1591-1598.

doi: 10.1097/IAE.0000000000001399 [Crossref]

11. Fernandes BF, Odashiro AN, Maloney $S$, Zajdenweber ME, Lopes AG, Burnier MN. Clinical-histopathological correlation in a case of Coats' disease. Diagnostic Pathol. 2006;1(1)1-4. doi: 10.1186/1746-1596-1-24 [Crossref] 
12. Steidl SM, Hirose T, Sang D, Hartnett E. Difficulties in excluding the diagnosis of retinoblastoma in cases of advanced Coats' disease: a clinicopathologic report. Ophthalmologica. $1996 ; 210(6) 336-340$.

doi: $10.1159 / 000310735$ [Crossref]

13. Shields JA, Eagle RC, Fammartino J, Shields CL, De Potter P. Coats' disease as a cause of anterior chamber cholesterolosis. Arch Ophthalmol. 1995;113(8)975-977. doi: $10.1001 /$ archopht.1995.01100080025014 [Crossref]
14. Adam RS, Kertes PJ, Lam WC. Observations on the management of Coats' disease- less is more. Brit J Ophthalmol. 2007;91(3)303-306.

doi: $10.1136 /$ bjo.2006.103382 [Crossref]

15. Mishra A, Aggarwal S, Shah S, Negi P, Bharwada $\mathrm{R}$, Desai N. An interesting case of Coats' disease. Med J Armed Forces India. $2015 ; 71(4) 384$.

doi: $\quad 10.1016 /$ j.mjafi.2013.11.010 [Crossref]

16. Mahajan S, Patel O, Sharma R, Kumar V. A Rare Case of Unilateral Adult Onset Coats' Disease. Sci J Delhi Ophthalmol Soc. 2018;28(3)67-68. doi: $10.7869 /$ djo.341 [Crossref] 